\title{
MUSEUM OF FOLK LAND TRANSPORT OF MIDDLE DNIEPER AREA OF THE NATIONAL HISTORICAL AND ETNOGRAPHIC RESERVE «PEREIASLAV»
}

\section{Luidmila Shkira ${ }^{1}$}

DOI: https://doi.org/10.30525/978-9934-588-11-2_36

The museum of the Folk Land Transport of the Middle Dnieper area, opened in 1993, represents a unique collection of vehicles of the nineteenth and twentieth centuries. The ideological inspirer and active seeker for vehicles was M.I. Zham.

It was under his leadership that a team of scientists collected exhibits and at the same time deepened knowledge about the material and spiritual culture of Ukrainians. As a result of fifty years of activity, Kiev, Poltava, Chernihiv, Zaporozhye, Sumy regions were surveyed, but most of the material was collected in Pereyaslav region.

In the center of the pavilion there is an observation path with different types of pavements - ground and paved with wood road, as well as pavement. Vehicles are systematized according to specific and constructive differences, functional purpose and traction force. The cartage (runner and wheeled) transport, is divided into household, industrial (hourse and ox transport), festive and passenger transport, is exhibited. A collection of hourse and ox harnesses is presented. In the complex with the transport units there is a production unit for manufacturing and servicing of vehiclts: a forge, a wheelman`s shop, and the place, where rims were steamed.

The main vehicles on land in Ukraine, were sleds in winter and carts in summer.The Slavic word that means sleigh derives from the wold that means a snake. The prototype of the oldest transport were draggers, the original form of which were cut down trunks of small trees, in them, as is in a hole, harnessed horses transported cargo. In Ancient Rus, riding on sleighs was considered more honorable than on wheel transport, so they were used during celebrations. Over time, on the flexible poles people began to fasten cross-bars, which already resembled sleds. Their construction was identical, the main components of them were two runners in which pegs were inserted, and «planks», which were put on them. There could be two or more planks, depending on the pegs, and on the box that was placed (made of boards or wicked). For Ukraine, horses and oxen sleigh were common, which in turn were divided into ore-horse (the animal were harnessed in the shafts) and two-horse ones (harnessed to the pole). Volk vehicles differed in size. For the manufacture of sleds, masters used the natural curvature of wood and processed it: steaming in a steam room and bending on the machine tools. Both the horse and the ox, as the means of transportation could be forged (according the length of the runners iron plates - were sewn). The wealthy peasants had special sleighs - the festive, so-called sleigh peaks, in the northern regions they were called «sledge-gliders», they were light, with thin

\footnotetext{
${ }^{1}$ National Historical and Ethnographic Reserve «Pereiaslav», Ukraine
} 
runners. In the exposition there are one-, two-, three-, six-seat sleds. They were used for the fair, wedding trips, children`s sledging.

Household sleighs - almost every owner had them. They transported hay, sheaves, manure, flrewood and other loads.

A sleigh without a back, but with a curved front and lateral poles, widely diverging from the front and increasing the size of the platform. Used for the transportation of light goods.

Cart - known on the territory of Ukraine since the 5-th century B.C. Its first forms were wheels made of logs. Varieties of carts depend on their chassis, that is, the connection of the axes with the help of wooden bars - poles or logs.

The cart consisted of front and rear parts which were connected with a pole. The gearbox had a slightiy smaller diameter of the wheels, which contained such parts: hubs, spokes, bent rims. On the axle a «bar-pillow», or a «nap», and on the top of it also a «loose pillow» were put on.

The exposition presents a scattering cart, whose rear and front wheels are joined by a «pole». It was intended for the transportation of wood, logs.

Garba served for the transportation of corn and light pottery. The cart has a ladder box. With a pole oxen and horses were harnessed.

Olympic chariot (quadriga) - was used in 1980 for the transportation of Olympic lights during the XXII Olympic Games.

Britchka («Bida») - a wooden-metal passenger carriage for one to two passengers.

Kotiga - a hut of branches on wheels, in which all the goods of shepherds, guards of the tubers were located.

Byndug - with a strong, wide and long platform for the transport of barrels, boxes. Owners of these vehicles were called «Bynduzhnyks».

Grabarka - has removable boards and a narrow long platform that provides quick and easy unloading of loose materials: sand, earth.

In the 90 's of the twentieth century researchers and restaurateurs of the reserve: M. Nerasko, M. Kichenko, F. Darda, V. Moskalenko, M. Svitko, Y. Kalinovich reproduced the Ghumak's cart, which reminds its main constructions, but has significant differences, big, strong, it was used for transportation for long distances, has a high solid box, decorated with carvings, covered from the top with an ox skin. In its manufacture, special attention was paid to the axis and wheel: the rims were made wide so that they pouched less in viscous soil. They were pulled by two or four oxen. The exhibition also presents the spring forms of transport of the beginning of the 20 -th century.

Twentieth century: Beztarka - for transportation of grain with a solid box of stretched boards. Side - a «window» with a lifted board.

Cypsy`s cart - (kibitka) - housing of the Gypsy family on wheels.

Fire Pump - a fire extinguishing device, liniyka - a cart-platform for the transport of passengers and light goods.

Tachanka - the origin of it is associated whith the word «tauricana» - the type of wheeled vehicles, which was used in the south of Ukraine. It had a couple or more 
horses, and the crew consisted of two or three people. The springs made it possible to move quickly through a dirty road and virgin, soil.

Used in national liberation competitions in Ukraine in 1917-1921 for close combat. A small, Phacton - a light four-wheder made in the city of Pereiaslav by the master Nikifor Gusakov in the early 20 -th century.

Sharaban - an open four-wheeled crew with transverse benches for easy and fast ride.

The attention is paid to things of road life, thanks to which visitors create a picture of living reality.

The exposition is complemented by the original paintings by Yury Grigorovich Legenky « The Way is a Fate of the Ukrainian People», which are scillfully executed on the walls and include fragments of songs.

The Museum of the Folk Land Transport of the Middle Dnieper is collecting, preserving, studying, exhibiting and promoting the creation of human hands that are connected with the history and practical development of technology and machinery. Therefore, visitors have the opportunity to get acquainted with interesting artifacts that will help them deepen their knowledge of the traditional Ukrainian culture and see vehicles that are no longer used in modern life in the XXI century.

\section{COLLECTION OF MONUMENTS OF FOLK WOODEN ARCHITECTURE OF THE MUSEUM OF FOLK ARCHITECTURE AND WAY OF LIFE OF MIDDLE NADDNIPRIANSCHYNA OF THE NATIONAL HISTORICAL AND ETNOGRAPHIC RESERVE «PEREIASLAV»)}

\section{Mykola Shkira ${ }^{1}$}

DOI: https://doi.org/10.30525/978-9934-588-11-2_37

Ukraine is extremely rich in the cultural and spiritual treasures that the people have treasured gathered over a thousand years of history. However, not all of them managed to survive, some of them came to us only in legends, photographs, or were simply destroyed by time. Some of them were fortunate enough to be preserved to this day.

One of such important elements of Ukrainian ethnicity is the original museum complex, which reproduces the true reality - the Research Branch of the Museum of Folk Architecture and Life of the Middle Dnieper region of National Historical and Ethnographic Reserve»Pereiaslav»,which construction started in 1964.

It is a significant research and cultural and educational institution covering extremely wide time frames: the development of the material and spiritual culture of

\footnotetext{
${ }^{1}$ National Historical and Ethnographic Reserve «Pereiaslav», Ukraine
} 